\title{
Effects of Imprinting Pressure on the Damage of Flexible Composite Mould and Pattern Quality during UV Nanoimprinting
}

\author{
Xu Zheng, Qing Wang * (i) and Wenquan Du \\ Institute of NanoEngineering, College of Civil Engineering and Architecture, Shandong University of Science \\ and Technology, Qingdao 266590, China; zhengxu081@163.com (X.Z.); 13021662108@163.com (W.D.) \\ * Correspondence: qwang@sdust.edu.cn; Tel.: +86-532-8605-7746
}

Received: 6 September 2019; Accepted: 15 October 2019; Published: 17 October 2019

\begin{abstract}
Imprinting pressure is the significant factor for composite mould durability and pattern quality during UV nanoimprinting on complex surfaces. To solve these problems, the effects of imprinting pressure on the damage of flexible composite mould and pattern quality-encountering particles were investigated through experiment and simulation. It was found that increasing the pressure could improve the pattern quality, but it will damage the mould and reduce the durability. Moreover, too small pressure could lead to serious pattern defects. Therefore, the imprint pressure of $30 \mathrm{kPa}$ was suitable for use in the imprinting process from the viewpoints of protecting the mould and reducing pattern defects. These findings will be useful for improving the pattern quality and mould durability.
\end{abstract}

Keywords: composite mould; pattern quality; imprinting pressure; UV nanoimprint

\section{Introduction}

The preparation of high quality and precision moulds is the core of nanoimprint lithography (NIL), and the hard mould and the soft mould are the widest applications at present [1,2]. In the case of the hard mould used for NIL under high temperature and pressure, it is not only easy to damage the mould, but also easy to cause pattern defects in the demoulding process [3-6]. For the soft mould, it can well meet the requirements in term of high throughput, low cost and the duplicate capability on curved surfaces [7-11]. However, the low elastic modulus and the poor durability limit the achievable resolution and lifetime [12-15]. The composite mould can be conformably contacted with a complex substrate compared to the hard mould, and its high Young's modulus ensures a higher pattern resolution compared to the soft mould. The composite mould extends the application range of nanoimprint from planar substrates to high-curvature surfaces or complex non-planar surfaces [16]. Therefore, the composite mould has a good application in the field of fabricating artificial compound eyes, hemispherical electronic eye cameras, photovoltaic devices, image sensor array, micro scale components, fiber optic sensor and other curved surface devices [17-20].

The flexible composite mould consists of a structural top layer and a flexible supporting backplane. Researchers successfully prepared high-resolution and curved patterns using hardpolydimethylsiloxane (H-PDMS)/PDMS, H-PDMS/acrylate and polyimide/Ormo composite moulds [21-23]. Although composite moulds can achieve higher resolution patterns on complex surfaces, defects such as interface separation and fracture of the support layer limit the application [24]. Furthermore, the damage of structural layer is caused by uneven substrates, and in particular, dust particles in the air cannot be ignored. The flexibility of the composite mould contributes to the replication of the pattern in the presence of particulate conditions, but it still causes damage to the 
pattern quality and mould durability. In this case, the setting of the imprinting pressure is a key factor for reducing the damage of the composite mould and improving the quality of the pattern. The objective of this research is to explore the effects of imprinting pressure on the damage of flexible composite mould and pattern quality encountering particle during UV-NIL.

In this paper, two major factors causing mould and pattern destruction in the imprinting process, i.e., the imprinting pressure and particles size were investigated through experiment. The maximum stress of composite mould during the imprting process was studied by finite element method (FEM) simulation of these two factors. The simulation results revealed the variation of the maximum stress and pattern damage range with various pressures and particles sizes. The simulation model and numerical results were useful for improving the pattern quality and mould durability

\section{Methods and Modeling}

\subsection{Experiment}

UV-NIL was used to explore the effects of imprinting pressures and particles on the pattern quality. As shown in Figure 1a, the UV resist (AZ5214E, AZ Electronic Materials, Somerville, USA) with the thickness of $1.4 \mu \mathrm{m}$ was spin-coated on the surface of silicon wafer at $4000 \mathrm{rpm}$ for $40 \mathrm{~s}$. Then, the $4 \mu \mathrm{m}$ particles were placed on the surface of UV resist. The PDMS/Ormo composite mould with a period of $5 \mu \mathrm{m}$ was employed during the UV-NIL process. Based on the neutral layer theory, the composite mould with $300 \mu \mathrm{m}$ support layer (PDMS) and $17 \mu \mathrm{m}$ structural layer (Ormo) were calculated for the experiments and simulation to reduce the interfacial damage of the mould during the imprinting process [25]. As shown in Figure 1b, the UV resist was imprinted and cured under the pressure of 50 and $200 \mathrm{kPa}$ for $10 \mathrm{~min}$ in the nanoimprinting equipment (NIL-150, Imprint Nano, Nanjing, China), respectively. The composite mould was separated from the patterned resist as shown in Figure 1c. It is found that the quality of the pattern will be greatly affected if particles are mixed during the imprinting process.
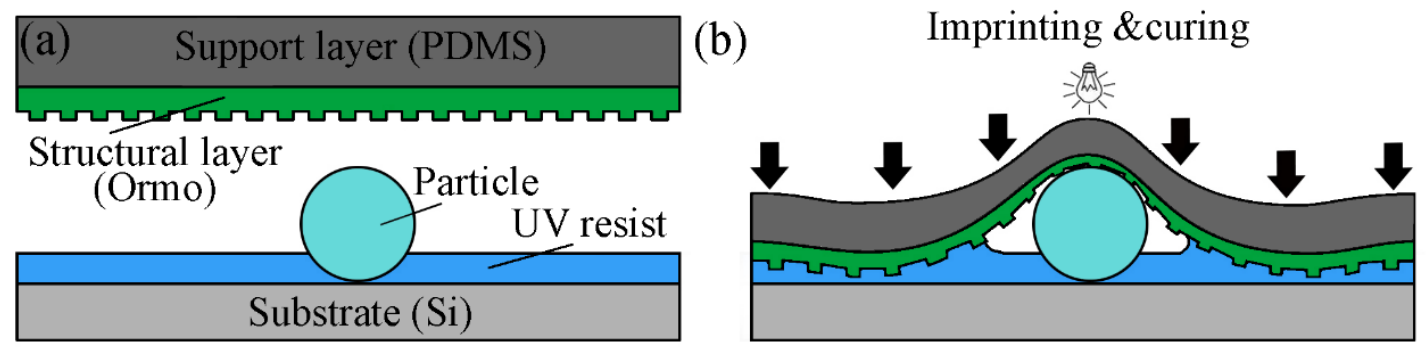

(c)

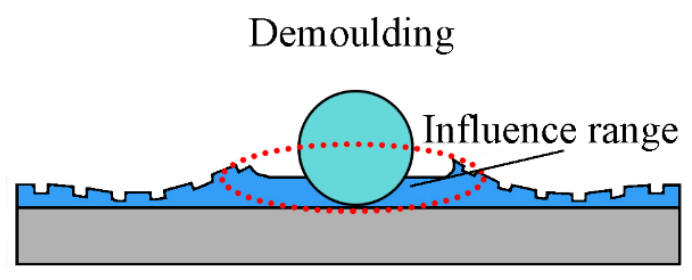

(d)

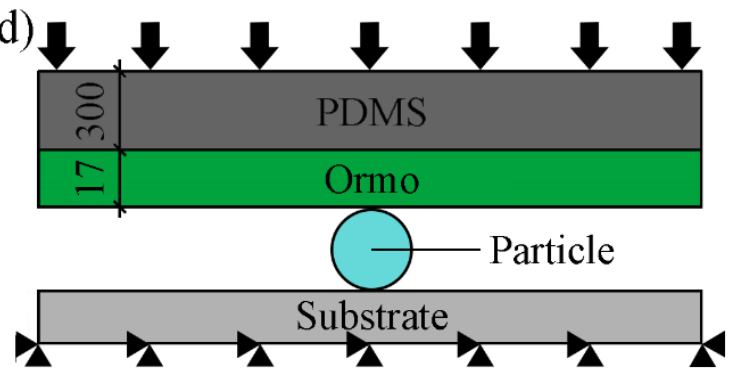

Figure 1. (a-c) schematic diagram of composite mould imprinting process encountered particles, (d) schematic diagram of geometric model and boundary condition in simulation.

\subsection{Numerical Simulation}

To explore factors affecting the quality of the pattern obtained after demoulding, the imprinting process with different pressures and particles were investigated by the finite element method (FEM) using ANSYS software (ANSYS 15.0, ANSYS, Pittsburgh, USA) [26,27]. As shown in Figure 1d, the geometrical model was established, which was consist of the support layer (PDMS, $300 \mu \mathrm{m}$ ) and 
structural layer (Ormo, $17 \mu \mathrm{m})$. The size of the PDMS in the model is the same as the thickness of the spin coating in experiment. In the simulation, the model is assumed to be uniform. Moreover, the PDMS and Ormo were defined as the rubber elastic material, and the particle and substrate were defined as rigid materials. The Mooney-Rivlin model was used to describe the PDMS and Ormo layers [28,29]. The Young's moduli and Poisson ratios are applied to demonstrate its mechanical properties. In all simulations, the Young's moduli of the PDMS layer and Ormo layer were 2 and $650 \mathrm{MPa}$, respectively. The Poisson ratios of the PDMS layer and Ormo layer were 0.45 and 0.22 , respectively.

Regarding the boundary conditions, the horizontal and vertical directions of the particle and substrate were fixed. The mould was a free boundary condition that could move freely in both horizontal and vertical directions. In the simulation, the element PLANE 42 was used to represent the particle and substrate, and the element PLANE 182 was used to represent the PDMS/Ormo composite mould. The contact element of CONTA 171 and TARGE169 ware applied for the interface between the PDMS/Ormo composite mould. To study the influences of the imprint pressure and particle radius on pattern quality, varied parameters were simulated. During the imprinting process, the uniform load was set on surface of composite mould from 10 to $100 \mathrm{kPa}$. The particle with radius of 2, 4, 6, and $8 \mu \mathrm{m}$ were investigated.

\section{Results and Discussions}

\subsection{Morphology of the Fabricated Grating Pattern}

Figure 2 shows the scanning electron microscopy (SEM) images of the mould and imprinted grating patterns with particles. As shown in Figure 2a, a $6 \mu \mathrm{m}$ diameter particle is adhered to the mould surface with a period of $5 \mu \mathrm{m}$. Figure $2 \mathrm{~b}$ shows that the grating pattern was damaged in a large area with the influence range of $80 \mu \mathrm{m}$ under a pressure of $50 \mathrm{kPa}$ when the particles radius of $4 \mu \mathrm{m}$. The main defects of the pattern are pattern loss and edge damage. The cause of this form of damage may be due to the low imprinting pressure. As shown in Figure 2c,d, the influence range decreases to 19 and $18 \mu \mathrm{m}$ when the pressure changes to 150 and $200 \mathrm{kPa}$. However, excessive pressure will not only cause cracks on the surface of the pattern but also cause damage to the mould. This result suggests that the imprinting pressure is an important factor affecting the quality of the pattern and the protection of the mould. Therefore, this influence factor was explored through imprinting on various particle sizes using FEM simulations.

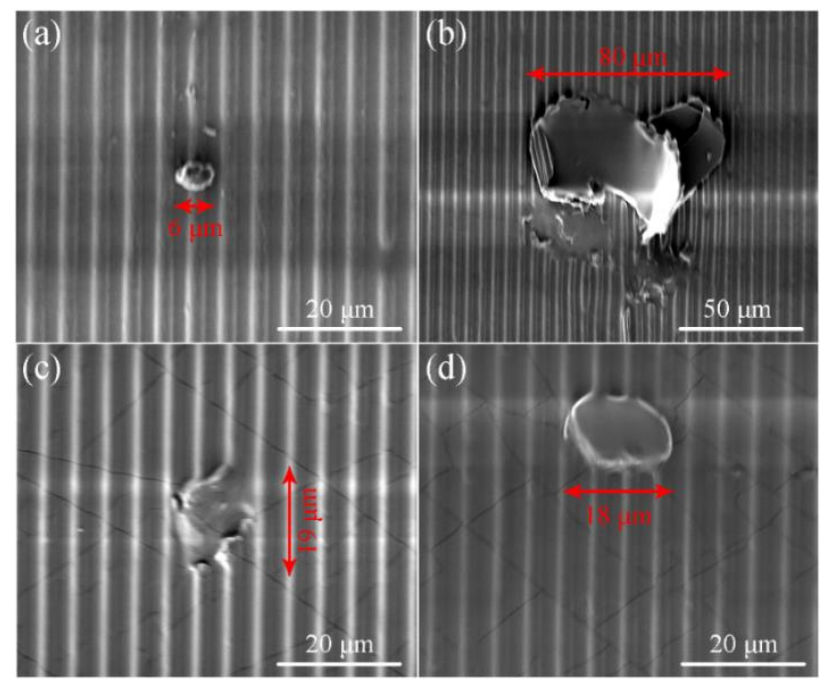

Figure 2. (a) Scanning electron microscopy (SEM) images of the mould with adheredparticle. SEM images of the grating patterns under the imprint pressure of (b) 50, (c) 150 and (d) $200 \mathrm{kPa}$ when the particles radius of $4 \mu \mathrm{m}$. 


\subsection{Von Mises Stress Distribution and Defects}

Figure 3a shows the von Mises stress distribution in composite mould with a pressure of $20 \mathrm{kPa}$ during the impringting process when the particle size is $6 \mu \mathrm{m}$. The stress is concentrated at the center of the structural layer (MX mark in Figure 4). The maximum stress value is $12 \mathrm{MPa}$ which is less than yield strength (50 MPa) of Ormo-structural layer. Therefore, the mould will only produce elastic deformation during the process of imprinting. However, the particle has a large influence range of $175 \mu \mathrm{m}$ which cause great defects in the pattern. Figure $3 \mathrm{~b}$ shows the von Mises stress distribution with a pressure of $80 \mathrm{kPa}$ when the particle size is $2 \mu \mathrm{m}$. The maximum stress at the center of the structural layer is $59 \mathrm{MPa}$ which is greater than the yield strength of $50 \mathrm{MPa}$. Although the influence range of the pattern is only $40 \mu \mathrm{m}$, the maximum stress will damage the mould.

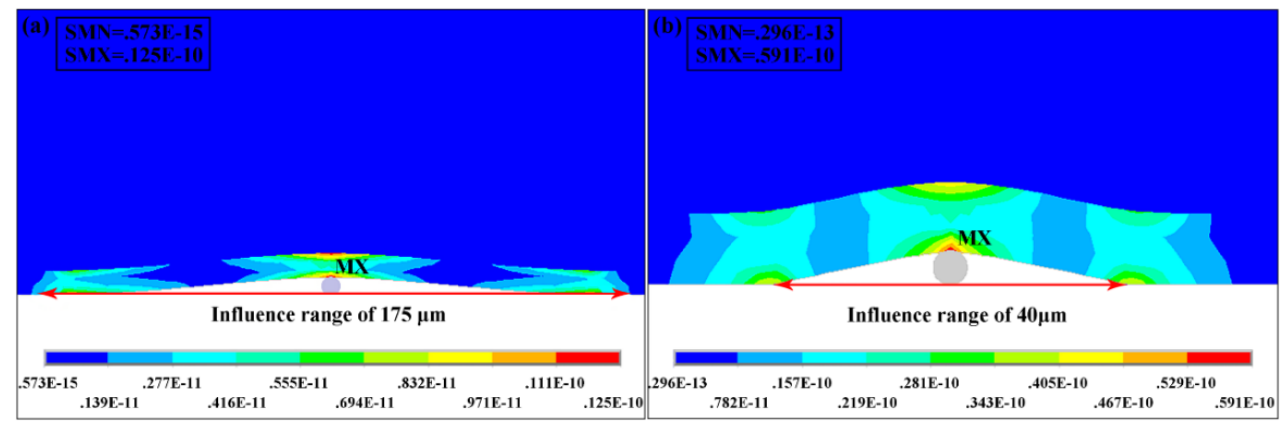

Figure 3. Von Mises stress distribution and influence range of composite mould for (a) particle radius of $6 \mu \mathrm{m}$ under the pressure of $20 \mathrm{kPa}$ and (b) particle radius of $2 \mu \mathrm{m}$ under the pressure of $80 \mathrm{kPa}$.

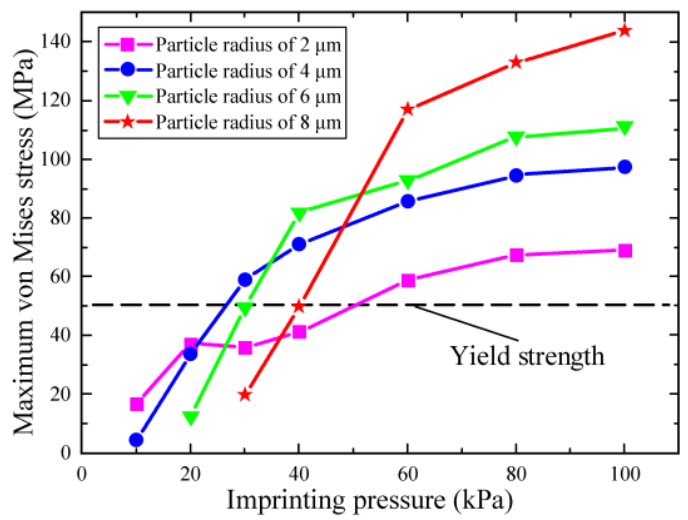

Figure 4. The maximum von Mises stress of composite mould for various pressures on the particles radius from 2 to $8 \mu \mathrm{m}$.

\subsection{Effects of Imprinting Pressure on Composite Mould}

To explore the effects on the maximum stress of composite mould and influence range of pattern, various particle sizes were simulated under the imprint pressures from 10 to $100 \mathrm{kPa}$ by the FEM. Figure 4 illustrates the maximum von Mises stress at the center of the composite mould, for particle radius ranging from 2 to $8 \mu \mathrm{m}$. It can be found that the maximum stress of the mould increases with increasing imprint pressure under the same particle size. The dashed line indicates the yield strength of the structural layer. The maximum stress is not obviously affected by particle size when the imprint pressure is lower than $40 \mathrm{kPa}$. However, the maximum stress of the structure layer increases significantly when the imprint pressure is greater than $40 \mathrm{kPa}$. The maximum stress value reaches $147 \mathrm{MPa}$ with $100 \mathrm{kPa}$ pressure under particle radius of $8 \mu \mathrm{m}$. The plastic deformation can cause the mould to be damaged when the maximum stress is greater than the yield strength. Therefore, the maximum stress of the mould is lower than $50 \mathrm{MPa}$ except for the particle radius is $4 \mu \mathrm{m}$ when the 
imprint pressure is $30 \mathrm{kPa}$. This indicates that the composite mould only exhibits elastic deformation during the imprinting process when the pressure is less than $30 \mathrm{kPa}$.

\subsection{Effects of Imprinting Pressure on Pattern Quality}

The imprinting pressure is also an important factor for the defects forming in the experimentally prepared patterns. Figure 5 shows the influence range of particle on the pattern under different imprint pressures. It can be found that the influence range decreases with the increasing of pressure, indicating the pressure can effectively reduce the effect of particles on pattern quality. Moreover, the contact area between structural layer and the substrate increases with an increase of pressure. As shown in Figure 5, when the pressure is $30 \mathrm{kPa}$, the influence range rapidly reduces to an acceptable range with the particle radius from 2 to $6 \mu \mathrm{m}$. Furthermore, increasing pressure has little effect on the influence range when the pressure is greater than $40 \mathrm{kPa}$. Moreover, according to the discussion above, the mould will be damaged when the pressure is greater than $30 \mathrm{kPa}$. Therefore, the imprinting pressure of $30 \mathrm{kPa}$ is suitable for use in the imprinting process from the viewpoints of protecting mould and reducing patterns defects.

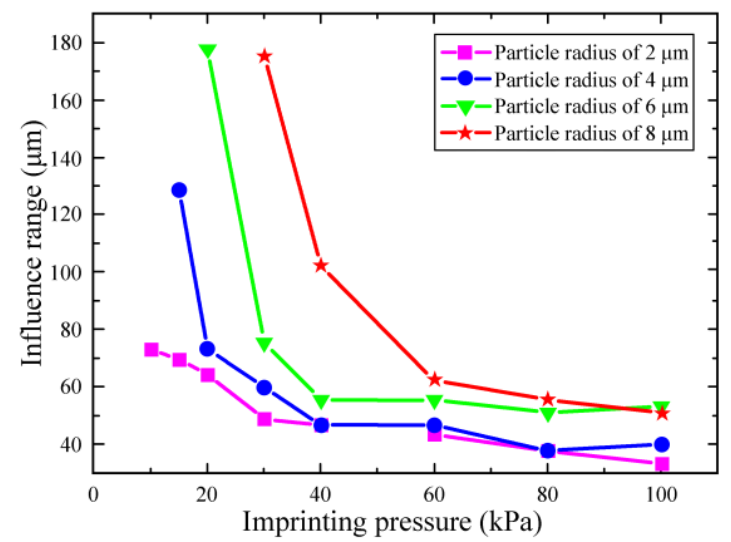

Figure 5. The influence range of fabricated patterns for various pressures on the particles radius from 2 to $8 \mu \mathrm{m}$.

\section{Conclusions}

A defective grating pattern was fabricated by UV-NIL on the UV resist with particles on the surface to simulate the dust encountered in the imprint experiment. It was found that excessive pressure could cause the mould to be damaged; too small pressure could lead to serious pattern defects. Therefore, imprinting pressure was an important factor affecting the quality of the pattern and the protection of the mould which were explored through imprinting on various particle sizes using FEM simulations. For a constant particle size, the maximum stress of the mould increased with the imprint pressure increased. When the imprint pressure exceeded $40 \mathrm{kPa}$, the maximum stress at the center of the structural layer was greater than the yield strength of $50 \mathrm{MPa}$ which caused the mould to be damaged with plastic deformation. However, the increasing pressure could effectively reduce the effect of particles on pattern quality. It was found that the influence range of particles rapidly reduced to an acceptable range with a particle radius from 2 to $6 \mu \mathrm{m}$ when the pressure was $30 \mathrm{kPa}$. Moreover, increasing pressure had little effect on the influence range when the pressure was greater than $40 \mathrm{kPa}$. Therefore, the imprint pressure of $30 \mathrm{kPa}$ was suitable for use in the imprinting process from the viewpoints of protecting mould and reducing patterns defects. These findings will be useful for improving the pattern quality and mould durability.

Author Contributions: Conceptualization, X.Z. and Q.W.; Methodology, X.Z. and W.D.; Formal analysis, X.Z. and W.D.; Investigation, X.Z. and W.D.; Resources, Q.W.; Data curation, X.Z. and W.D.; Writing-original draft preparation, X.Z.; Writing-review and editing, Q.W. and X.Z.; Visualization, X.Z. and W.D.; Supervision, Q.W.; Project administration, Q.W. 
Funding: This work was supported by the Taishan Scholar Project of Shandong Province (No. TSHW20130956) and Natural Science Foundation of Shandong Province, China (No. ZR2017MA013).

Conflicts of Interest: The authors declare no competing financial interest.

\section{References}

1. Yu, C.C.; Chen, H.L. Nanoimprint technology for patterning functional materials and its applications. Microelectron. Eng. 2015, 132, 98-119. [CrossRef]

2. Lan, H.; Liu, H. UV-nanoimprint lithography: Structure, materials and fabrication of flexible molds. J. Nanosci. Nanotechnol. 2013, 13, 3145-3172. [CrossRef] [PubMed]

3. Mekaru, H. Formation of metal nanostructures by high-temperature imprinting. Microsyst. Technol. 2014, 20, 1103-1109. [CrossRef]

4. Zheng, X.; Wang, Q.; Zhang, R.; Ma, L.; Luan, J. Effects of aspect ratio and metal layer thickness on demoulding of metal/polymer bilayer gratings during nanoimprinting. Sci. Rep. 2018, 8, 12720. [CrossRef]

5. Kim, K.S.; Kim, J.H.; Lee, H.J.; Lee, S.R. Tribology issues in nanoimprint lithography. J. Mech. Sci. Technol. 2010, 24, 5-12. [CrossRef]

6. Wang, Q.; Zheng, X.; Zhang, R.; Zhang, J.; Ma, L.; Liu, H. Analysis of the metal/polymer bi-layer structure during demolding process of nanoimprinting. J. Photopolym. Sci. Technol. 2015, 28, 763-767. [CrossRef]

7. Bhingardive, V.; Menahem, L.; Schvartzman, M. Soft thermal nanoimprint lithography using a nanocomposite mold. Nano Res. 2018, 11, 2705-2714. [CrossRef]

8. Maurer, J.H.M.; González-García, L.; Reiser, B.; Kanelidis, I.; Kraus, T. Templated self-assembly of ultrathin gold nanowires by nanoimprinting for transparent flexible electronics. Nano Lett. 2016, 16, 2921-2925. [CrossRef]

9. Fernández, A.; Medina, J.; Benkel, C.; Guttmann, M.; Bilenberg, B.; Thamdrup, L.H.; Nielsen, T.; Torres, C.M.S.; Kehagias, N. Residual layer-free reverse nanoimprint lithography on silicon and metal-coated substrates. Microelectron. Eng. 2015, 132, 56-61. [CrossRef]

10. Song, J.; Lu, H.; Li, S.; Tan, L.; Gruverman, A.; Ducharme, S. Fabrication of ferroelectric polymer nanostructures on flexible substrates by soft-mold reverse nanoimprint lithography. Nanotechnology 2016, 27, 015302. [CrossRef]

11. Zhu, J.; Bai, Y.; Zhang, L.; Song, Z.; Liu, H.; Zhou, J.; Lin, T.; Liu, Q.H. Large-scale uniform silver nanocave array for visible light refractive index sensing using soft UV nanoimprint. IEEE Photonics J. 2016, 8, 1-7. [CrossRef]

12. Eriksson, T.; Yamada, S.; Krishnan, P.V.; Ramasamy, S.; Heidari, B. High volume nanoimprint lithography on III/V substrates: Imprint fidelity and stamp lifetime. Microelectron. Eng. 2011, 88, 293-299. [CrossRef]

13. Ji, R.; Hornung, M.; Verschuuren, M.A.; Laar, R.; Eekelen, J.; Plachetka, U.; Moeller, M.; Moormann, C. UV enhanced substrate conformal imprint lithography (UV-SCIL) technique for photonic crystals patterning in LED manufacturing. Microelectron. Eng. 2010, 87, 963-967. [CrossRef]

14. Cegielski, P.J.; Bolten, J.; Kim, J.W.; Schlachter, F.; Nowak, C.; Wahlbrink, T.; Giesecke, A.L.; Lemme, M.C. Overlay accuracy limitations of soft stamp UV nanoimprint lithography and circumvention strategies for device applications. Microelectron. Eng. 2018, 197, 83-86. [CrossRef]

15. Förthner, M.; Papenheim, M.; Rumler, M.; Stumpf, F.; Baier, L.; Rommel, M.; Scheer, H.C.; Frey, L. Polymerization related deformations in multilayer soft stamps for nanoimprint. J. Appl. Phys. 2017, 122, 165305. [CrossRef]

16. Zou, Y.; Zhang, D.; Lin, H.; Li, L.; Moreel, L.; Zhou, J.; Du, Q.; Ogbuu, O.; Danto, S.; Musgraves, D.; et al. High-performance, high-index-contrast chalcogenide glass photonics on silicon and unconventional non-planar substrates. Adv. Opt. Mater. 2014, 2, 478-486. [CrossRef]

17. Zheng, X.; Wang, Q.; Luan, J.; Li, Y.; Wang, N.; Zhang, R. Angle-dependent structural colors in a nanoscale-grating photonic crystal fabricated by reverse nanoimprint technology. Beilstein J. Nanotechnol. 2019, 10, 1211-1216. [CrossRef]

18. Kuo, W.K.; Hsu, C.J. Two-dimensional grating guided-mode resonance tunable filter. Opt. Express 2017, 25, 29642-29649. [CrossRef]

19. Zheng, X.; Wang, Q.; Luan, J.; Li, Y.; Wang, N. Patterned metal/polymer strain sensor with good flexibility, mechanical stability and repeatability for human motion detection. Micromachines 2019, 10, 472. [CrossRef] 
20. Guo, P.; Zheng, Y.; Liu, C.; Ju, J.; Jiang, L. Directional shedding-off of water on natural/bio-mimetic taper-ratchet array surfaces. Soft Matter 2012, 8, 1770-1775. [CrossRef]

21. Odom, T.W.; Thalladi, V.R.; Love, J.C.; Whitesides, G.M. Generation of 30-50 nm structures using easily fabricated, composite PDMS masks. J. Am. Chem. Soc. 2002, 124, 12112-12113. [CrossRef] [PubMed]

22. Li, Z.; Gu, Y.; Wang, L. Hybrid nanoimprint-soft lithography with sub-15 nm resolution. Nano Lett. 2009, 9 , 2306-2310. [CrossRef] [PubMed]

23. Papenheim, M.; Steinberg, C.; Dhima, K.; Wang, S.; Scheer, H.C. Flexible composite stamp for thermal nanoimprint lithography based on OrmoStamp. J. Vac. Sci. Technol. B 2015, 33, 06F601. [CrossRef]

24. Papenheim, M.; Mayer, A.; Wang, S.; Steinberg, C.; Scheer, H.C. Flat and highly flexible composite stamps for nanoimprint, their preparation and their limits. J. Vac. Sci. Technol. B 2016, 34, 06K406. [CrossRef]

25. Papenheim, M.; Eidemüller, W.; Wang, S.; Steinberg, C.; Scheer, H.C. Reducing the risk of failure with flexible composite stamps. Microelectron. Eng. 2016, 155, 79-84. [CrossRef]

26. Ma, L.; Wang, Q.; Zhang, R.; Zheng, X.; Zheng, T. Effects of contact states on polymer pattern deformation during demolding process in nanoimprint lithography. J. Vac. Sci. Technol. B 2016, 34, 06K409. [CrossRef]

27. Wang, Q.; Zhang, Y.; Zheng, X.; Ma, L.; Zhang, R. Influence of template modulus of elasticity on polymer filling, deformation and stress distribution. J. Photopolym. Sci. Technol. 2018, 31, 19-26. [CrossRef]

28. Mooney, M. A Theory of large elastic deformation. Appl. Phys. 1940, 11, 582-592. [CrossRef]

29. Rivlin, R.S. Large elastic deformation of isotropic materials VI. Further results in the theory of torsion, shear and flexure. Philos. Trans. R. Soc. Lond. 1949, 242, 173-195. [CrossRef]

(C) 2019 by the authors. Licensee MDPI, Basel, Switzerland. This article is an open access article distributed under the terms and conditions of the Creative Commons Attribution (CC BY) license (http://creativecommons.org/licenses/by/4.0/). 